Open Scientist Handbook • OSH

\title{
As an open scientist, you're good-to-get what you need
}

\author{
Bruce R. Caron
}

Published on: Mar 09, 2021

DOI: $10.21428 / 8 b b b 7 f 85 . f 86 c 9 b e 8$

License: Creative Commons Attribution 4.0 International License (CC-BY 4.0). 


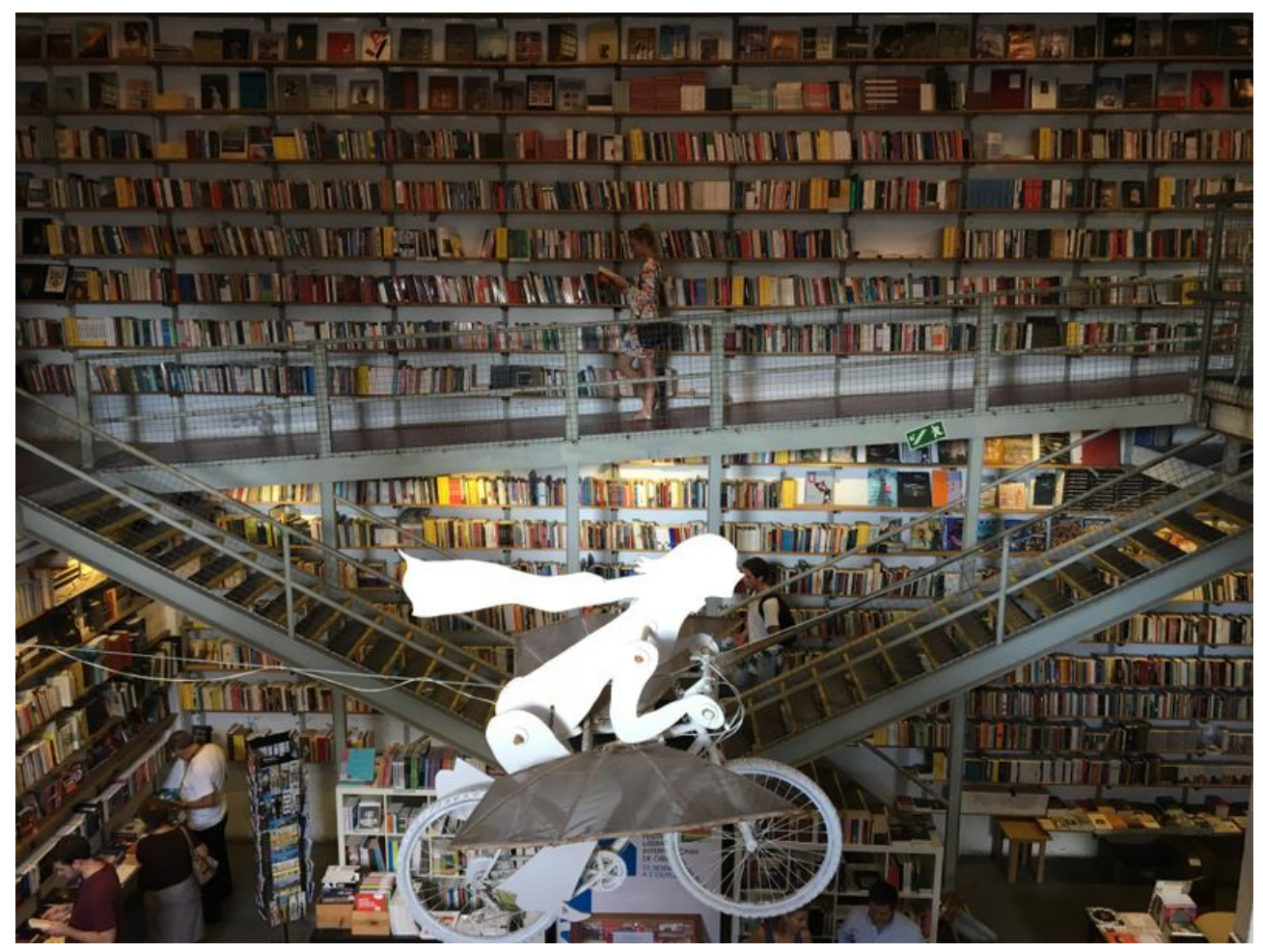

You're a scientist, with a license to give and get...

“After giving talks about open science I've sometimes been approached by skeptics who say, 'Why would I help out my competitors by sharing ideas and data on these new websites? Isn't that just inviting other people to steal my data, or to scoop me? Only someone naive could think this will ever be widespread.' As things currently stand, there's a lot of truth to this point of view. But it's also important to understand its limits. What these skeptics forget is that they already freely share their ideas and discoveries, whenever they publish papers describing their own scientific work. They're so stuck inside the citation-measurement-reward system for papers that they view it as a natural law, and forget that it's socially constructed. It's an agreement. And because it's a social agreement, that agreement can be changed. All that's needed for open science to succeed is for the sharing of scientific knowledge in new media to carry the same kind of cachet that papers do today" (Nielson 2011).

[T]he work of culture more generally may be seen as training towards letting (things) go. If culture is all about conveying things and skills to others...then learning to let go of things that others appropriately demand is a permanent 
process. Just as those from whom I have received skills and knowledge (and positions and objects and my life) had to let go of their possessions in the course of their lives, so will I have to learn to let go..." (Widlok 2016).

In this Handbook, there is a lot of description of the future, open academy within a gift economy. If this sounds like an open scientist needs to spend their career giving away their knowledge, that's actually pretty much spot on. But the other, equal, side to this is that an open scientist also gets to get what they need to do their research and build their life. The practice of getting-to-get as a feature of open science culture needs to be explored. What is clear is that this "half" of the gift economy in an abundant open academy is by far the bigger half. It's like putting your potato in the common pot and getting a feast in return. Think of this gift economy as a loan-and-borrow economy, instead of a give-and-take economy. When you share, you also get to keep what you share, and when you borrow, you have no exclusive claim on what you've get: just a promise that there is more out there to use. Below, we will discover how this works.

"Saul Bellow, writing to a friend ... said: "The name of the game is Give All. You are welcome to all my facts. You know them, I give them to you. If you have the strength to pick them up, take them with my blessing'" (Lethem 2007; Accessed July 20, 2020).

\section{Artists steal, scientists give and get}

In his book Steal like an Artist, Auston Kleon (2012) reminds artists that their lives have been surrounded by art, and that their "original" ideas have been informed in myriad ways by their exposure to this. Stealing is unavoidable, so do it right.

Additionally, new art (including music) is always positioned inside of and/or away from the art preceding this. There is an abundance of influences to use, and a debt to all of them. Artists need to be bold and remix what they find, to celebrate the old ideas in their new work. And like science, an artist borrows from the best in order to improve on this using their creative imaginations.

Today, within the academy, stealing practices—the hoarding, scooping, credit-grabbing kinds that are supported by the invented scarcity of ideas and the diminished value for generosity in science-flourish in the absence of social attention and alternative cultural norms. Tomorrow, when open science defines the norms for borrowing, sharing, and celebrated reuse, stealing can be banished to the social margins, and ridiculed as needed. 
Borrowing is the main form of sharing in the academy's gift economy. Investigate the meanings and potentials of what you find, and then transform these from those insights born of your personal onlyness (See: The Onlyness of the Career Open Scientist). Science is very much like an art here, with a similar relationship to its ideas, but a greater need to maintain the provenance of its knowledge goods. Everything in your science life is borrowed: the knowledge, the methods, every insight up to the point when you add your own, the data you collect. So your job is to learn how to borrow as a scientist.

You are a scientist. You're not agent 007. You are really more like agent $\mathrm{C}_{20} \mathrm{H}_{25} \mathrm{~N}_{3} \mathrm{O}$. But you do have a license. A license to borrow. Come closer. Be honest. You are always on the lookout for ideas worth borrowing. If the journal article you're reading is not worth borrowing, toss it away and keep looking. You are always looking. It's called "research." You hope your own team's ideas are worth borrowing. You make borrowing these easy. It's called "publication." You are a professional thief. You keep careful track of the ideas you borrow. You know where they are from. You've read the articles, you've read the articles they cited. You've read the articles from the citations in those articles. Life would be a lot easier if you could just spin up new ideas on your own. It doesn't work that way.

Borrowing as a scientist in the open-science economy means you get to ask for and take what you need, in culturally specific ways. You take resources to use and reuse, to mine and remix. You pull knowledge from these, and add insights to them in the process. In hunter-gatherer societies (and sometimes in college dormitories), this is called "tolerated scrounging." In the academy it's more like "celebrated reuse." Openscience research repositories make reuse quick and easy, and they are filled with ideas worth borrowing. And, since these are "non-rivalrous" (See: Neylon 2016), an unlimited number of scientists can borrow them. Better still, the more these ideas are borrowed, the greater their value.

The culturally specific rules for borrowing are being fashioned through the governance processes of scholarly commons (대olarly commons), as these are created to steward common pooled resources toward optimal use. The removal of patents for basic research (See: Hyde 2009; Barnett 2020), is one starting point. Fully public openaccess publishing is another. Start somewhere and grow a culture of tolerated scrounging for the resources in your scholarly commons.

"We may consider sharing to be tolerated scrounging but for the scrounging to be tolerated it has to build on a number of recognized modes of action and 
interaction" (Widlok 2013).

\section{The responsibility is yours, the credit belongs to the whole scholarly club}

[R]esearchers saw maintaining responsible conduct as the mandatory responsibility of every individual scientist. By choosing this card, the discussants assumed that science's most important responsibility to society was to produce reliable knowledge. Research misconduct is then seen as the main threat to this practice..." (Sigl et al 2020).

When you gift (publish) a new scholarly work, you shoulder every responsibility for the rigor in your methods and any issues with your data. This is the first of several social responsibilities (such as mentoring others) you always carry, and one of the keystone virtues the academy has demanded for hundreds of years. Still, you are not the first nor the final author of your own findings. That authority is attached to a thousand places in the prior ideas of others, and in the work of more scientists yet to happen. You merely added one piece to an ongoing solution to the puzzle of nature (or society, etc.): to the "one long experiment" (Martin 1998) that is science. Time to get humble; but if intellectual humility doesn't sound like you, you can claim "hypo-egoic nonentitlement" (Banker and Leary 2019) instead.

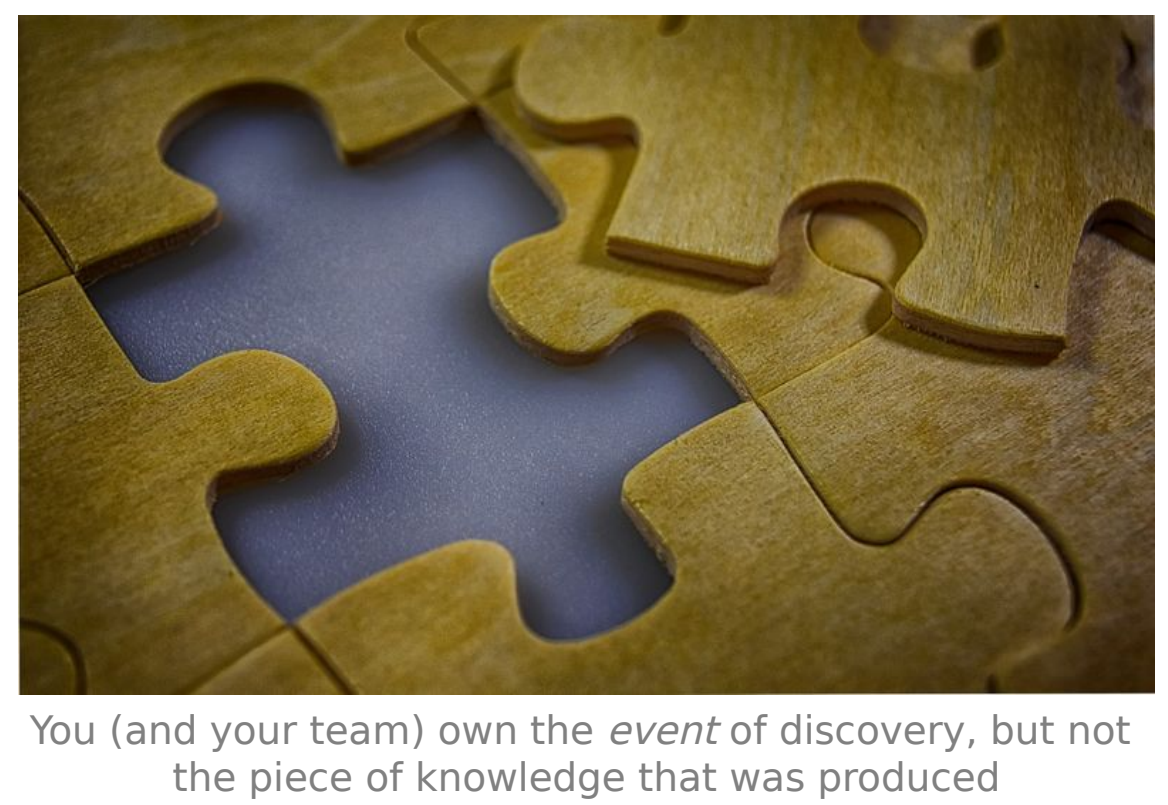

Borrowing like a scientist in an open gift economy also means everyone else gets to borrow from you. When they borrow like scientists, this makes you happy. It means your works are borrow-worthy. You celebrate their reuse. In fact you need others to reuse your work to show its reproducibility. Your claim is that anyone would 
necessarily arrive at the very same insight you had, proving that this insight has a durable purchase on its object. If nobody can or does reuse your work, its value is unknown and even suspect.

What is harder to admit is the amount of luck, the confluence of good fortune that brought you to the event where you and your team acquired some new insight (Pluchino A. et al. 2018). Nobody gets to own serendipity. "Serendipity is a category used to describe discoveries that occur at the intersection of chance and wisdom" (Copeland 2019). Riding on the back of the serendipity of reading what you did, talking with whom you have, and trying something new, you've exercised rigor and wonder and perseverance enough through your research to find that one distinct piece of the puzzle to apply it exactly where it fits. Now, you are expected to honor and celebrate the many contemporary and prior ideas that helped you and your team arrive at the singular event within which this new insight was born (See: Shaming the giant). By this, you also show that you belong to the elite club of science. And those who borrow your ideas will honor and celebrate them in theirs.

\section{Commoning needs to get and give to work}

As an open scientist, you have five jobs:

1. produce ideas worth borrowing, and;

2. make these ideas as easy to borrow as possible;

3. borrow as much from other scientists as you need, but borrow like a scientist;

4. become an active maintainer in your commons, to keep the borrowing opportunities rich and rewarding for everyone.

5. as a member of a scholarly commons, you also have the duty to create normative cultural practices to optimize borrowing going forward.

Your list of "good getting" practices will be fashioned to meet the needs of all the commoners in your community. Here's a sample list: 


\section{GETTING}

nead all the work you can in youn field

cite as much as possible everything you use

credit goes to all members of youn team emphasize that youn findings are based on the work of others

neuse and credit the methods you've borrowed from a colleague

find someone's data and neuse/remix this with attribution

build on existing open software. enhancing this with new code

work toward badges, not prizes

when offered a prize. insist that the whole team be necognized

\section{STEALING}

grab and publish as original the findings from someone else's work that you've neviewed

take content from a funding neview panel and submit youn oun proposal elsewhere

copy ideas from conference posters without atthibution

credit youn grad student's work as youn oun

demand to be forst author on a team paper

hoard your oun data

insist youn lab-built nesearch software is proprietary

patent your basic nesearch

Getting practices involve care and attention to the provenance of what's being borrowed, and active credit for those who have made borrowing possible. Stealing practices all point to a game of personal gain based on hiding the sources of your own learning. Getting as a scientist aims to steward the abundance of open resources is a long-term-longer than any lifetime-practice. 


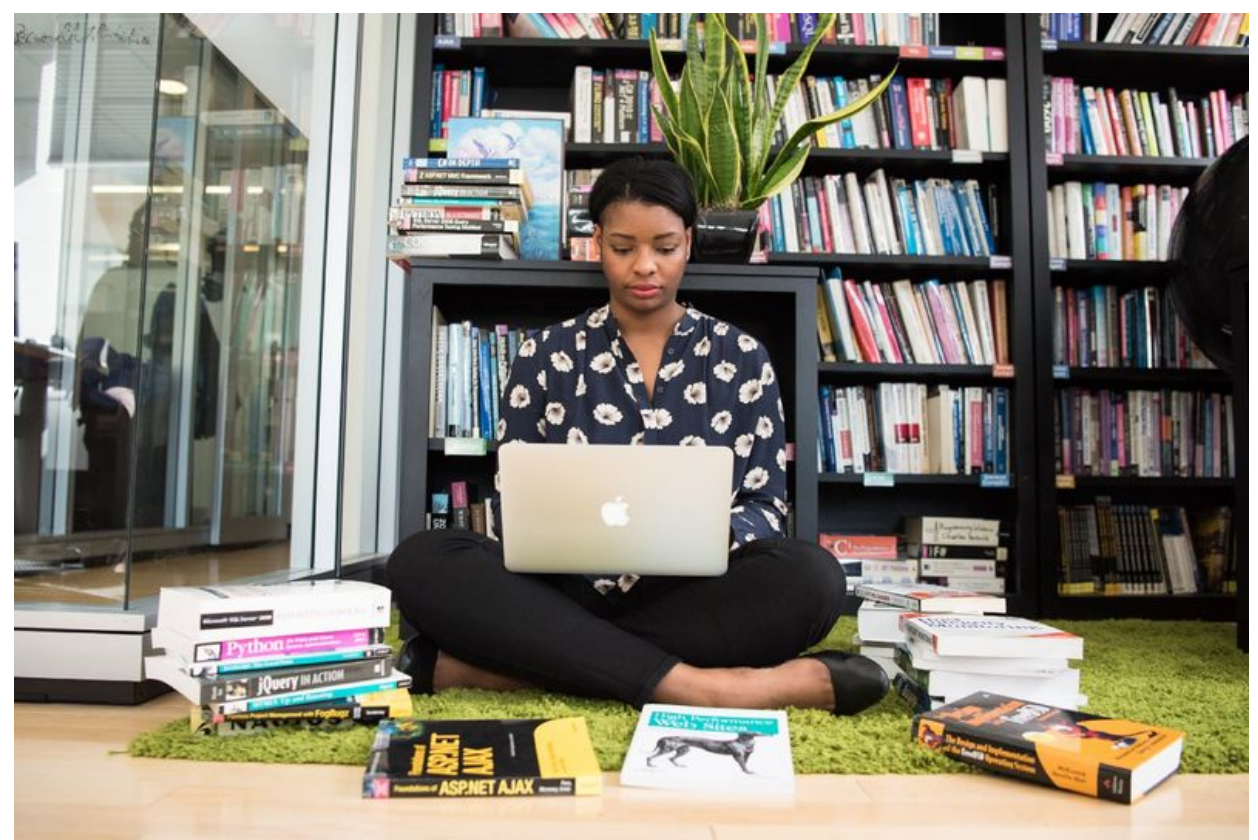

Tolerated scrounging (celebrated reuse) takes time and effort

\section{On disinterestedness: the freedom to discover and share in (open) science}

"Disinterestedness: Scientists are motivated by the desire for knowledge and discovery, and not by the possibility of personal gain.

Self-Interestedness: Scientists compete with others in the same field for funding and recognition of their achievements" (Anderson, et al. 2007).

Let's dig a little deeper into "celebrated reuse" and the history of science. The Mertonian norms of science include a notion of "disinterestedness." At the time Merton was writing, this norm announced a basic freedom to pursue science without conflicts of interests, to shield basic science research from the motivations and (perverse) incentives that come with the marketplace, say, or with other external social/political/military desires. As Vannevar Bush (Accessed August 1, 2020) noted: "Scientific progress on a broad front results from the free play of free intellects, working on subjects of their own choice, in the manner dictated by their curiosity for exploration of the unknown." Disinterestedness is also the culturally valued attitude of "letting go" when others build on your findings.

Disinterestedness was, and still is, the classic norm that frees you to let others in the academy club borrow your work. The same lack of self interest that validates your independent research choice also validates you being able to let other people freely use your work. Since you chose to not let external interests determine your research path, you have no reason to hoard the results. 
Disinterestedness is one of the social costs of academic freedom (you probably can't have one without the other). It is the reason why the imbalance between responsibility (you have 100\% of this) and authority (you have very little of this) makes perfect sense. You take the freedom to choose your research path in exchange for gifting the results back to the community; you release your personal interest in these results to benefit the whole scientific club.

If self-interest is your main incentive to do science, you are not doing open-science. Worse than that, you are doing science wrong. If you decide to wait until you have tenure to throw off self-interest (Anderson et al 2010), you are also doing it wrong. Certainly, we all have a stake in our own interests. Science expects us to care for these interests outside of our scientific explorations, and we need institutional reform and support to get there. But mainly, disinterestedness tells us to avoid conflicts with interests from outside the "republic of science" (Polanyi 1962).

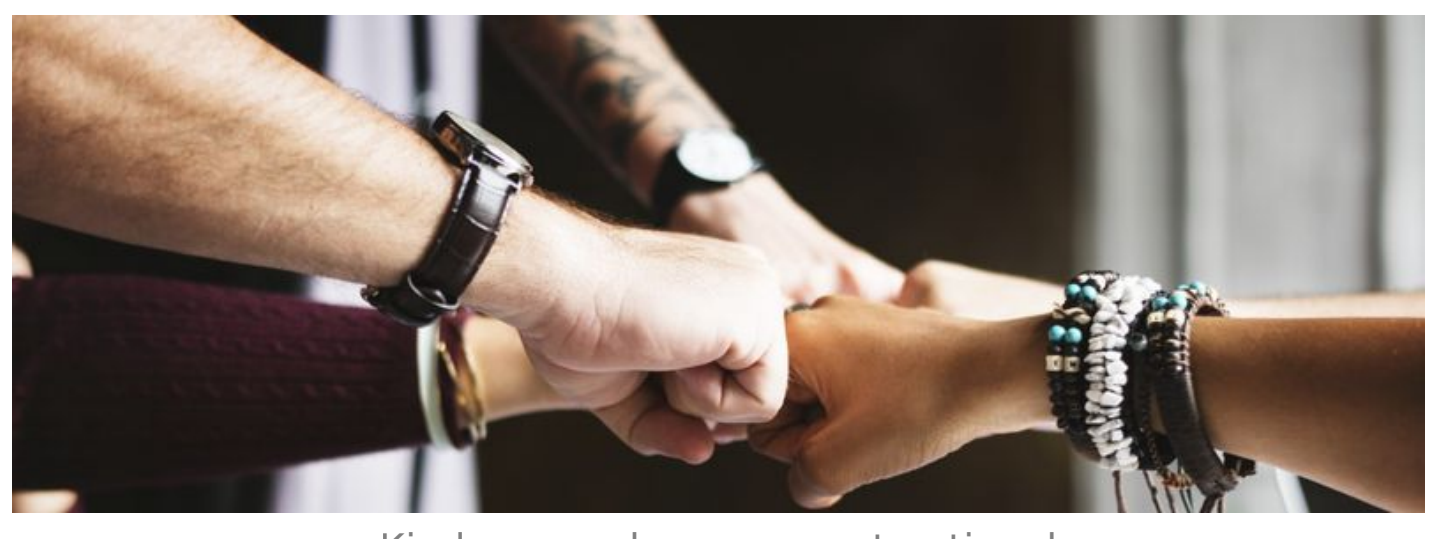

Kindness and care are not optional

"[M]uch of academic thinking brackets issues of emotions and values outside of academic understanding, even though emotions and values inhabit research and teaching by virtue of what we know, what we choose not to know, what we prioritise and what we trivialise" (Lynch and Ivancheva 2016).

Research needs to be free to follow its own objects, but being passionate about your research is no free ticket to act poorly with others (See: Six rules about passion in the workplace). Not caring about the marketplace and not caring for your colleagues are two different practices.

Disinterestedness is not an alibi to ignore/resist other organizational cultural values for the academy, values that include kindness and care in academy workplaces and in relations with colleagues. You can start by bracketing out the perverse marketplace incentives that might warp your research path and diminish your own passion for the 
pursuit of science. Passion is another part of science that is not peculiar to you. You are not the only person in the room or on your team that has been infected with the intellectual disease of science. This is a long-term global knowledge pandemic. Everyone gets to be infected-to be passionate-in their own way. Exploring these passions through years of rigorous research effort builds a kind of shared practical wisdom inside the profession.

\section{Applied practical wisdom: the practice of open science}

The practical wisdom that underpins actually doing science removes the need for other incentives. The answer to the question: "How do you incentivize scientists to do research and teaching?" is simply this: "give them more opportunities to learn the practical wisdom required to do science" (See: The practical wisdom of science praxis). Science requires/rewards its own unique practical wisdom. In addition to the practical wisdom one might (and perhaps should) acquire through social experiences with others (colleagues, family, strangers), doing science offers opportunities to acquire practical wisdom through a career experiencing nature as a complex emergent system.

For many years, you borrowed learning from your teachers. Now, you encourage your students to scrounge new knowledge. Today, you borrow like a scientist: information from your objects of study and insights from conversations with your colleagues. In tomorrow's open-science culture, culturally-informed practices for getting-to-get will help you and your team and your organization optimize the use of the emergent scholarly commons infrastructure and content. The work needed to articulate and support these practices will be significant. But know that the work needed support stealing in the academy today is just as arduous, except that so many academics have already learned how. Unlearning these toxic cultural practices will take time and reflection.

Today, dozens of open-science platforms and communities are encouraging effective reuse. Reuse is one metric that deserves to become a goal (and one goal that makes a handy metric). How does your organization, your discipline, or your team celebrate active reuse? Where can it improve?

Open Scientist Handbook References 